\title{
LA PARTICIPACIÓN COMO ELEMENTO CLAVE EN LAS ESCUELAS DEMOCRÁTICAS
}

\author{
Arecia Aguirre García-Carpintero ${ }^{1}$ \\ Daniel Schugurensky² ${ }^{2}$
}

\section{Resumen}

A veinte años de la muerte de Paulo Freire, rescatamos un elemento central de su pensamiento pedagógico: su convencimiento de que la educación puede hacer una valiosa contribución a la formación de sujetos democráticos y eventualmente a la construcción de una sociedad más justa y democrática. Freire decía que la educación no cambia el mundo pero cambia a las personas que van a cambiar el mundo. Así, es posible argumentar que la educación no democratiza a la sociedad pero puede generar personas más democráticas que van a construir sociedades más democráticas. Esta relación entre el nivel micro (la construcción de personas más democráticas) y el nivel macro (la construcción de sociedades más democráticas) puede ser mediada, al nivel meso, por la democratización de las escuelas y los sistemas educativos. Este texto aborda estas relaciones, y está organizado en cinco secciones. La primera describe las preocupaciones teóricas y prácticas de Freire en relación al proyecto democratizador. La segunda analiza las conexiones entre democracia, participación y educación ciudadana. La tercera explora la participación estudiantil las escuelas. La cuarta examina los presupuestos participativos escolares. La última sección presenta un resumen y algunas conclusiones preliminares.

\footnotetext{
Abstract

On the $20^{\text {th }}$ anniversary of the passing of Paulo Freire, in this article we highlight a central feature of his pedagogical thinking: his conviction that education can make a contribution to the

1 Profesora del Área de Teoría e Historia de la Educación, Doctora en Educación, Universitat Jaume I Departamento de Educación, Avd. Vicent Sos Baynat s/n Castelló 12071, Castellón de la Plana, España. E-mail: aaguirre@uji.es.

${ }^{2}$ Daniel Schugurensky, Professor and Coordinator of the Graduate Certificate in Participatory Governance, Ph.D in Education, Arizona State University, AZ, United States, Arizona State University, Tempe Campus, Tempe, AZ 85281. E-mail: dschugur@asu.edu

Revista Reflexão e Ação, Santa Cruz do Sul, v. 25, n. 2, p. 46-83, Maio./Ago. 2017. http://online.unisc.br/seer/index.php/reflex/index
} 
development of democratic subjects and eventually to the construction of a more just and democratic society. Freire used to say that education does not change the world but it changes people who are going to change the world. Thus, it is possible to argue that education does not democratize society but can nurture more democratic people who are going to build more democratic societies. This relationship between the micro-level (nurturing democratic citizens) and the macro-level (building more democratic societies) can be mediated, at the meso-level, by the democratization of educational institutions and systems. This paper addresses these relationships, and is organized into five sections. The first describes Freire's theoretical and practical contributions in relation to the democratizing project. The second analyzes the connections between democracy, participation and civic education. The third explores student participation in schools. The fourth examines participatory school budgets, and the last section presents a summary and preliminary conclusions.

\section{INTRODUCCIÓN}

A veinte años de la muerte de Paulo Freire, y en el contexto de este dossier homenaje organizado por la Revista Reflexão e Ação, creemos relevante rescatar uno de los elementos centrales de su pensamiento pedagógico: su convencimiento de que la educación puede hacer una valiosa contribución a la formación de sujetos democráticos y eventualmente a la construcción de una sociedad más justa y democrática. Parafraseando a Freire, quien solía decir que la educación no cambia el mundo pero cambia a las personas que van a cambiar el mundo, es posible argumentar que la educación no democratiza a la sociedad pero puede generar personas más democráticas que van a construir sociedades más democráticas. Esta relación entre el nivel micro (la construcción de personas más democráticas) y el nivel macro (la construcción de sociedades más democráticas) puede ser mediada, al nivel meso, por la democratización de las escuelas y los sistemas educativos.

Este texto aborda estas relaciones, y está organizado en cinco secciones. En la primera describimos brevemente las preocupaciones teóricas y prácticas de Freire en relación al proyecto democratizador. En la segunda analiza las conexiones entre democracia, participación y educación ciudadana. La tercera sección explora el tema de la participación estudiantil las escuelas, y la siguiente sección continúa esta exploración haciendo hincapié en el caso de los 
presupuestos participativos escolares. La quinta y última sección presenta un resumen y algunas conclusiones preliminares.

\section{FREIRE Y ELO PROYECTO DEMOCRATIZADOR}

A lo largo de su vida, Freire siempre tuvo un interés por la democratización de instituciones educativas. Ya en sus primeros trabajos en el departamento de Educación y Cultura del SESI (Serviço Social da Industria) a mediados del siglo XX, cuando era un joven lleno de inquietudes e iniciativas, Freire implementó un modelo de gestión abierto y democrático en el cual se invitaba a participar a los estudiantes y a sus familias. Durante ese periodo en SESI, Freire también creó un 'club de los trabajadores' en el cual sus miembros podían analizar conjuntamente sus problemas y buscar soluciones en forma colectiva. Aún en un contexto institucional adverso, Freire intentó reorientar al SESI hacia un modelo de funcionamiento basado en los principios de la autogestión, el diálogo y la "parlamentarización" (entendida como una combinación de grupos de estudio y equipos de acción). Estos tres principios, argumentaba Freire en su tesis doctoral "Educação e Atualidade Brasileira", debían ejercerse cotidianamente para promover la democratización de la sociedad brasileña (FREIRE, 1959; GERHARDT, 1993). En esa tesis, Freire argumentó que la educación para la democracia no podía separarse de la práctica de la democracia, y que la democracia se puede aprender de manera más efectiva a través de la participación activa en la vida política y social, incluyendo asociaciones barriales, sindicatos, grupos comunitarios, clubes recreativos y también instituciones educativas, el tema que nos ocupa en este trabajo. Sin embargo, debido a las críticas que despertó su modelo de gestión democrática, Freire se vio obligado a renunciar a su cargo en el SESI. Unos años más tarde, en Educación como Práctica de la Libertad, Freire (1973, p. 36) reflexionó nuevamente sobre el aprendizaje de la democracia, y concluyó que dicho aprendizaje sólo puede asimilarse a través de la experiencia.

Es interesante destacar que casi medio siglo después de su trabajo en el SESI, Freire volvió a tener la oportunidad de ejercer un cargo de responsibilidad en el área educativa (esta vez como Secretario de Educación de la ciudad de Sao Paulo durante el mandato de Luiza Erundina), procuró nuevamente democratizar la gestión educativa, especialmente a través de una iniciativa denominada "Escuela Ciudadana". Como en su previo intento, su propuesta nuevamente fue resistida por actores sociales claves -incluyendo a medios de comunicación, políticos de partidos 
opositores al gobierno, administradores educativos y docentes- quienes estaban acostumbrados a estructuras y procesos más tradicionales y jerárquicos. Al igual que en su previa experiencia democratizadora, eventualmente Freire se vio obligado a renunciar (O’CADIZ et al, 1998).

Estas dos experiencias frustradas que Freire vivió a mediados y a fines del siglo XX nos recuerdan que el camino hacia la democratización de las instituciones educativas no sólo es largo y sinuoso, sino que además está lleno de espinas. En estos momentos, a fines de la segunda década del siglo XXI, han transcurrido prácticamente cien años desde que John Dewey escribió Democracy and Education, un importante texto que llegó a Freire gracias a Anisio Texeira, quien había estudiado en Columbia Teachers College. También ha transcurrido un siglo desde que León Tolstoy creó una serie de escuelas democráticas en Yasnaya Polyana (Rusia), desde que Francisco Ferrer creó la Escuela Moderna en Barcelona, desde que Emma Goldman fundó la Escuela Moderna Ferrer en Nueva York, y desde que A.S. Neill creó una escuela democrática y autogobernada en Summerhill (Inglaterra). Pese a esos intentos pioneros y a muchos otros experimentos llevados a cabo a los largo del siglo pasado, y pese a los ríos de tinta que se han derramado defendiendo las ideas de una educación progresista y democrática, en la práctica cotidiana no se han logrado avances significativos. Salvo algunas notables excepciones, en la actualidad la mayoría de los sistemas educativos y centros escolares de todo el planeta siguen siendo jerárquicos, la educación para la ciudadanía democrática sigue teniendo baja prioridad, y los estudiantes tienen escasas oportunidades de vivir experiencias democráticas. Este último elemento es particularmente relevante, porque como señalaba Dewey, una de las mejores formas de aprender la democracia es haciendo democracia. Si bien Dewey articuló coherentemente una teoría sobre la importancia de la experiencia en el aprendizaje, el reconocimiento de esta relación es bastante más antigua, y nos lleva a autores como Rousseau, Aristóteles o aún Confucio, quien hace 2,500 años decía "dímelo y lo olvidaré; muéstramelo y lo recordaré; involúcrame y lo aprenderé”. Si la educación es entendida como praxis, “acción y reflexión de hombres y mujeres sobre el mundo para transformarlo (FREIRE 1970), uno de los desafíos de la educación para la ciudadanía democrática consiste justamente en el diseño de propuestas pedagógicas que involucren a los estudiantes en prácticas democráticas genuinas y en la reflexión crítica sobre dicha práctica.

\section{DEMOCRACIA, PARTCIPACIÓN Y APRENDIZAJES CIUDADANOS}

Revista Reflexão e Ação, Santa Cruz do Sul, v. 25, n. 2, p. 65-83, Maio./Ago. 2017. http://online.unisc.br/seer/index.php/reflex/index 
En un contexto caracterizado -tanto a nivel internacional como nacional- por la hegemonía de la lógica y las políticas neoliberales, es posible observar la desaparición de espacios y valores comunitarios, la pérdida de paulatina de derechos laborales y civiles, y una transición hacia modelos de relacionamiento social más individualistas y competitivos que privilegian lo privado por sobre lo público y exacerban las desigualdades. En este contexto, el ejercicio ciudadano de la democracia generalmente se reduce a emitir un voto cada cuatro años para elegir representantes que en no pocos casos responden a grupos económicos poderosos. En el período que transcurre entre una elección y la siguiente, los ciudadanos se marchan a sus casas y observan la vida política desde la sala de su casa por la televisión. Para la mayoría de la gente, la democracia entre elecciones consiste en un espectáculo al cual asisten como silenciosos espectadores, una rutina que se rompe de vez en cuando si salen a la calle a protestar por alguna injusticia o cuando sienten que sus derechos han sido vulnerados. Si bien reconocemos la necesidad de la representación política y reivindicamos el derecho a la protesta, creemos que la democracia es más que una forma de gobierno. Como señalaba Dewey (1995, p. 98), "la democracia es un estilo moral y un modo de vida comunitario. En otras palabras, es una manera de vivir asociativamente y una experiencia comunicada conjuntamente."

En este mismo sentido, VIEJO, MARTÍ-COSTA, PARÉS, RESENDE; VILAREGUT (2009) argumentan que la democracia no es un estado de cosas inmutable que se prescribe en una constitución, sino más bien un método para adoptar decisiones políticas fundado en cierta garantías y procedimientos. Por ello, la democracia no se acaba en las instituciones sino que va más allá porque constituye la capacidad de la comunidad para poder responder a los problemas colectivos en el espacio que sea. Esto resalta la necesidad de explorar y potenciar formas de organización social que favorezcan la reconstrucción de vínculos así como la articulación de sentidos colectivos de pertenencia que respeten la autonomía individual (SUBIRATS 2005). Por tanto, es importante avanzar en nuevas formas de participación colectiva y de innovación democrática que no se desvinculen de las condiciones de vida de la gente.

La democracia participativa puede considerarse como una ampliación del sistema democrático formal que posibilita la participación ciudadana, generalmente a partir de espacios generados desde las instituciones. Esta característica es un arma de doble filo, porque si por un lado abre el Estado a la comunidad, también puede degradar el sentido de participación 
democrática que pretende si se convierte en un espacio demasiado institucionalizado, burocrático y restrictivo. Por supuesto, tampoco se trata de desplazar a las instituciones del estado al banco de suplentes, sino que acepten el hecho de que una nueva sociedad civil organizada puede ser incorporada al escenario de una gobernanza cooperativa y relacional (ARANGUREN, 2010). Por eso, la democracia participativa corre el riesgo de perder su sentido si la pensamos únicamente desde las restricciones que frecuentemente imponen las instituciones y si sólo intentamos buscar estrategias para mejorar los canales de comunicación entre las instituciones y la sociedad. Ello es necesario, pero también es importante reconocer y promover la capacidad democrática de la ciudadanía de organizarse y actuar. Con frecuencia las instituciones públicas prefieren ignorar todo el trabajo y la energía que hay detrás de una ciudadanía organizada, pero en ocasiones los aprovecha como espacios de democracia participativa real, potenciando los medios reales que permitan que la ciudadanía ejerza la democracia (WACQUANT, 2005). Para que la ciudadanía entienda a la democracia como pleno derecho debe sentirla y vivirla, y para ello necesitamos diferentes modos de convivencia que generen una construcción desde la autonomía y el sentido colectivo facilitando la pluralidad de voces desde el día a día. Estos procesos reforzarían el aprendizaje de la participación porque, como decíamos antes, a participar se aprende participando.

Así, la participación no sólo genera vínculos comunitarios sino también aprendizajes significativos (WENGER, 2001; SERRANO, 2008; LLENA; PARCERISA; ÚCAR, 2009; LERNER; SCHUGURENSKY, 2007). En este punto, es importante clarificar que entendemos a la participación no sólo como un medio de aprendizaje sino también, y fundamentalmente, como un derecho ciudadano. Esto implica una participación real, y no únicamente una invitación que puede amparar planteamientos paternalistas o manipuladores (LLENA; PARCERISA; ÚCAR, 2009). Así, siguiendo a Alberich (2004), entendemos a la participación ciudadana como el conjunto de actividades, procesos y técnicas por los que la población interviene en los asuntos públicos que le afectan. El desafío organizativo y pedagógico consiste en diseñar e implementar ese conjunto de actividades, procesos y técnicas para que la sociedad civil participe efectivamente. En este punto consideramos oportuno diferenciar entre participación social y participación ciudadana. La primera se refiere a cualquier acto, fenómeno o proceso colectivo de participación de la sociedad, como por ejemplo un acto de protesta, una manifestación, un festival de música o una actividad recreativa o deportiva. La participación ciudadana sería una parte de la 
participación social que afecta directamente a la comunidad y se ejerce en relación con la administración pública (ALBERICH; ESPADAS 2011). De lo que se trata es de transformar la realidad social desde el espacio público favoreciendo la construcción colectiva de una ciudadanía activa y orientada a la justicia.

También es pertinente distinguir entre espacio público y administración pública. En griego, público quiere decir expuesto a la mirada de la comunidad, a su juicio y aprobación. El espacio público es el espacio cívico del bien común, por contraposición al espacio privado de los intereses particulares. El espacio público es un lugar de encuentro de la ciudadanía, pero ello requiere dinamizar una cultura de participación en la cual se aprenda a convivir entre diferentes (DELORS, 1995) y que eventualmente se convierta en una forma de vivir. Como señalan LÓPEZ; LEÓN, 2009), cuando las personas no trascienden su individualidad integrándose activamente en una asociación, renuncian a la construcción de una cultura colectiva que integra sus peculiaridades individuales formando un todo diferente a la suma de sus partes.

A medida que las personas se implican con ese colectivo, su esfuerzo por formar parte del espacio tiende a crecer, y lo mismo sucede con su compromiso con la comunidad y su conciencia sobre la importancia de su participación. De este modo se amplían sus horizontes y se despliegan nuevas trayectorias de aprendizaje a través de procesos continuos de deliberación, toma de decisiones, reflexión y transformación de las comunidades. También aumenta el sentimiento de pertenencia al colectivo en un lento proceso de tránsito desde la periferia hacia el centro del mismo, proceso que LAVE; WENGER (1991) denominan aprendizaje situado. Se trata también de un proceso multidimensional de empoderamiento cultural que, tal como lo planteaba Pestalozzi, involucra simultáneamente el pensamiento, la afectividad y la acción.

En síntesis, la participación democrática y los aprendizajes ciudadanos van de la mano. la concepción de una democracia radical implica una forma de vivir en la cual la horizontalidad de las relaciones participativas debe estar presente en diversos momentos de lo cotidiano y no sólo en las instituciones políticas (PATEMAN 1970). Aunque la democracia radical haga referencia a la propia dinámica de construcción conjunta desde espacios para dialogar y cooperar y satisfacer las necesidades de la gente (CALLE, 2007), una de las preguntas es cómo llevar a cabo esta participación para conseguir democratizar el día a día de la ciudadanía y su vida social. Esto no es fácil, porque la democracia participativa supone ciudadanos con derechos que se perciban a sí mismos como actores y no como espectadores. Si en la escuela aprendemos principalmente a 
competir y a obedecer instrucciones, es difícil que nos percibamos como sujetos colectivos solidarios que pueden ser sujetos de su propia historia. Por ello la escuela, y especialmente la escuela pública, debe promover estructuras y procesos para la participación democrática.

\section{LA PARTCIPACIÓN EN CENTROS ESCOLARES: UNA PERSPECTIVA FREIRIANA}

Como decíamos anteriormente, a pesar de las miles de páginas que se han publicado en los últimos cien años sobre la necesidad de democratizar los centros educativos y de formar ciudadanos activos, en la mayoría de los países del mundo, las escuelas públicas aún están lejos de ser espacios que promuevan el diálogo, la participación y la reflexión crítica. Por ejemplo, hace unos años, en una encuesta a 220 alumnos del nivel medio de Argentina, se preguntaba por los tres principales problemas en sus escuelas. La respuesta mas frecuente, antes que otras como "falta de equipamiento e infraestructura", "ausencia de docentes por paros" o "desorden y agresividad entre compañeros", fue "métodos de enseñanza que se adaptan a una actitud pasiva de los alumnos inhibiéndose la reflexión sobre los distintos temas" (COZZA; SANTACHITA 2011). En gran parte, esta situación se debe a que los sistemas educativos conciben a los alumnos como futuros ciudadanos, y por ello entienden que su misión es prepararlos para que adquieran los conocimientos y habilidades que les permitan enfrentarse a los problemas del futuro, cuando sean adultos.

Como observaba Dewey (2004, p. 9), esta concepción de la educación como "preparatoria" para la sociedad del futuro puede sacrificar el desarrollo de las capacidades que tienen los estudiantes para resolver problemas del presente. Se produce así una disociación entre escuela y vida, en la cual la escuela es el presente y la vida es el futuro. No es infrecuente que en los discursos de graduación de la escuela secundaria -o aún de la universidad- algún adulto les brinde consejos a los estudiantes con frases que comienzan con un "ahora que van a entrar a la vida..." o "ahora que se van a integrar a la sociedad..." Esta conceptualización de los estudiantes como "futuros ciudadanos" ignora que los niños y jóvenes pueden contribuir al fortalecimiento de la democracia y pueden ejercer su ciudadanía en la medida de sus capacidades y sus intereses. Ls experiencia internacional indica que el tránsito de una ciudadanía pasiva a una ciudadanía activa no necesita esperar hasta que las personas se conviertan en personas adultas según lo definan las leyes de cada estado-nación. Aspectos centrales de la vida democrática como el diálogo, la 
deliberación, el análisis crítico de la información, la toma de decisiones colectivas, la inclusión, el respeto al otro o la búsqueda del bien común pueden comenzar a ejercitarse en la escuela. Por ello, en la concepción de Dewey la escuela, por encontrarse en el corazón de cada comunidad, tiene un papel central en la construcción de una democracia creativa.

Desde esta perspectiva, la educación es una iniciación a la vida en grupo que nos expone por primera vez a una vida en comunidad. En las escuelas, los estudiantes vivencian el primer encuentro con la sociedad y a través de la participación tienen la oportunidad de comenzar a construir su autonomía y a entender el significado de lo colectivo. Considerando que la escuela puede crear el ambiente de la sociedad que deseamos, si lo que queremos es forjar una sociedad democrática, el ambiente de la escuela tendrá necesariamente que ser democrático. Si queremos conseguir y mantener una forma de vida democrática, necesitamos oportunidades para aprenderla y practicarla. Desde esta perspectiva, la escuela se convierte en un lugar idóneo donde aprender los fundamentos de la vida democrática a través de su práctica cotidiana (DEWEY, 1995; FREIRE, 1997; GADOTTI, 2005). Así, la cultura colaborativa, el liderazgo inclusivo y las prácticas democráticas pueden considerarse como elementos clave que aumentan la autonomía de la comunidad educativa en procesos participativos emprendidos desde un enfoque educativo democrático (MOLINER et al., 2016). Con el paso del tiempo, a medida que adquieren experiencia de participación, las personas y colectivos implicados mejoran sus habilidades para tomar decisiones complejas y se van convirtiendo en protagonistas de los procesos decisorios escolares (GALE; DENSMORE, 2007). Es preciso aclarar que cuando hablamos de experiencias de participación en la comunidad educativa las entendemos como algo más que el puro formalismo de las reuniones establecidas en los consejos escolares y las comisiones que se derivan. Estamos hablando de procesos y herramientas inclusivos que posibiliten una mayor implicación y participación democrática del alumnado, el profesorado, las familias y otros agentes comunitarios y que permitan analizar la realidad social y adquirir habilidades de gestión colectiva.

En sus escritos y en su práctica Freire desarrolló muchas de estas ideas, especialmente la importancia del trabajo en grupo, el diálogo, la acción reflexiva, la cooperación, la concientización, el conocimiento local y el desarrollo comunitario en el proyecto de humanización, emancipación y transformación social. Para él, como para Dewey, la escuela no sólo debería ser una institución que estimule la curiosidad, la rigurosidad, la crítica, la creatividad 
y la alegría a través del aprendizaje, sino que también podría convertirse en un lugar privilegiado de participación ciudadana y responsabilidad cívica. Para que esto suceda es preciso crear espacios de diálogo, horizontalidad y toma de decisiones colectivas en los cuales los participantes de la comunidad educativa puedan analizar su realidad, reflexionar sobre la misma, responsabilizarse de ella y actuar para mejorarla. Estos espacios, para ser efectivos, deberían dinamizar la participación de la comunidad educativa a través del compromiso, la responsabilidad y el liderazgo distribuido. Al mismo tiempo, estos procesos participativos deben entenderse como procesos educativos a través de los cuales la comunidad educativa aprende a comprometerse, a responsabilizarse y a organizarse desde principios democráticos y de justicia social. En síntesis, una escuela democrática puede contribuir a formar ciudadanos y ciudadanas que activen procesos continuos de democratización a través de dinámicas abiertas y en constante reconstrucción (GUARRO, 2005).

Como señalábamos anteriormente, Freire intentó hacer realidad estas ideas en varias ocasiones, especialmente a través del proyecto de Escuela Ciudadana, que se inició en Sao Paulo a principios de los noventa y luego fue adoptado - con distintas variantes- en varios municipios de Brasil. Las escuelas ciudadanas estaban guiadas por una serie de principios entre los cuales se encontraban partir de las necesidades de los estudiantes y de las comunidades circundantes, entender a la educación como una actividad de producción (y no solamente de transmisión) de conocimientos, generar un currículum más interdisciplinario, y promover una gestión escolar más democrática y participativa (GADOTTI, 2002). Unos meses antes de morir, en una entrevista concedida a la TV educativa de Río de Janeiro el 19 de marzo de 1997, Freire explicó su concepción de la escuela ciudadana:

La Escuela Ciudadana es aquella que se asume como un centro de derechos y de deberes. Lo que la caracteriza es la formación para la ciudadanía. La Escuela Ciudadana, entonces, es una escuela que hace realizable la ciudadanía de quien está en ella y de quien viene a ella. Ella no puede ser una escuela ciudadana en sí y para sí. Ella es ciudadana en la medida misma en que se ejercita en la construcción de la ciudadanía de la que usa su espacio. La Escuela Ciudadana es una escuela coherente con la libertad. Es coherente con su discurso formador, liberador. Es toda escuela que, esforzándose para ser ella misma, lucha para que los educandos-educadores también sean ellos mismos. Y como ninguno puede serlo solo, una Escuela Ciudadana es 
una escuela de comunidad, de compañerismo. Es una escuela de producción común del saber y de la libertad. Es una escuela que vive la experiencia tensa de la democracia.

La escuela ciudadana implica también una transición de una cultura individualista y competitiva a una cultura colaborativa y solidaria. El análisis de las experiencias de escuelas en transformación sugiere que dicha transición tiene tres elementos clave: la asunción colectiva del proyecto, la pluralidad de voces desde la tolerancia y la empatía, y la transparencia informativa que incluye confianza y corresponsabilidad (BENJAMIN, 2002; TRAVER; SALES; MOLINER, 2010). En el libro Cartas a quien pretende enseñar, cuyo título original en portugués era Professora sim, tia não: cartas a quem ousa ensinar, Freire decía que los docentes deberían dar testimonio permanente de los valores de la democracia. En la séptima carta, Freire admite que realmente es muy difícil hacer democracia porque la democracia, como cualquier sueño, no se hace con palabras sino con la reflexión y con la práctica. En esa carta a los docentes, Freire señala que nadie vive la democracia plenamente ni la ayuda a crecer si se le censura su derecho de tener voz, y por ello sugiere que sólo se puede construir una escuela más democrática si los docentes dialogan con los educandos. Su argumento es que sólo cuando los docentes escuchen a los educandos podrán ser oídos por ellos (FREIRE 1997, p. 114). En un estudio reciente que se focalizó en el caso de Porto Alegre, FISCHMAN; GANDIN (2016) concluyen que el énfasis del Proyecto de Escuela Ciudadana en la participación y la democratización generó un cambio radical respecto del sistema de educación pública tradicional de Brasil. Una de las herramientas de la escuela ciudadana es el presupuesto participativo escolar.

\section{LOS PRESUPUESTOS PARTICIPATIVOS ESCOLARES}

Si bien reconocemos que una gestión escolar más democrática y participativa requiere la participación concertada de estudiantes, docentes, personal no-docente, padres y miembros de la comunidad, en este trabajo nos concentramos en la participación de los estudiantes. Tradicionalmente, la participación de los estudiantes en las escuelas ha tenido dos grandes expresiones. La primera es el centro de estudiantes, cuya principal función es representar a los estudiantes frente a las autoridades de los establecimientos. La segunda son las actividades extracurriculares, que abren espacios de participación estudiantil artísticos en diferentes áreas 
(deportivas, artísticas, ecológicas, comunicacionales, etc.), para que los jóvenes utilicen el tiempo libre en forma creativa, fomentando la identificación y pertenencia con el establecimiento educacional (ZAMORA 2016). En las últimas décadas ha surgido un tercer canal de participación estudiantil que vincula la gestión democrática de la institución escolar con los aprendizajes ciudadanos: el presupuesto participativo escolar.

Las primeras experiencias de presupuesto participativo escolar pueden encontrarse a fines del siglo XX y principios del siglo XXI en Brasil, en ciudades como Sao Paulo, Porto Alegre, Recife, Barra Mansa, Santos o Belo Horizonte. Como sucedió con el presupuesto participativo y con el presupuesto participativo juvenil, con el tiempo la práctica del presupuesto participativo escolar ha sido adoptada por otros países, y en estos momentos existen procesos en escuelas de Chile, Argentina, Ecuador, Colombia, Perú, España, Portugal, Francia, México, Canadá y Estados Unidos, entre otros lugares. Es posible pronosticar que la expansión del presupuesto participativo escolar tomará bastante tiempo, pues aún existen reticencias por parte de muchos directivos y docentes a que estudiantes de primaria y secundaria asuman responsabilidades que según ellos pertenecen exclusivamente a las personas adultas, con el argumento de que todavía no están preparados. Sin embargo, en los establecimientos educativos en los que se han desarrollado estos procesos se ha demostrado que los niños y jóvenes toman decisiones maduras. Por lo general son capaces de presentar buenas propuestas, de mostrarse solidarios y preocupados por el medio ambiente y por el bien común, y tienden a votar proyectos que mejoran las condiciones de enseñanza-aprendizaje y del entorno escolar (JAIMOVICH, 2005; PINEDA, 2009; LÓPEZ, 2012; PAÑO; YÁÑEZ, 2014, COHEN et al., 2015). También resulta gratamente sorprendente observar en estas experiencias la mejora de actitudes y los altos niveles de participación de muchos estudiantes considerados académicamente como "malos alumnos". (GARCÍA; PEREZ; DE ALBA, 2012).

En el contexto escolar, la participación debe considerarse no sólo como una situación pedagógica, instrumental o procesual sino también como un derecho de los niños y jóvenes en tanto actores sociales y como un instrumento para democratizar la institución escolar. Por ello, los objetivos del presupuesto participativo escolar giran simultáneamente en torno a tres sistemas. El primero está vinculado al reconocimiento y ejercicio de la ciudadanía de niños y jóvenes como sujetos de derecho. El segundo consiste en la dimensión pedagógica de estos procesos. El tercero considera al presupuesto participativo como un espacio que permite promover y desarrollar 
estrategias de involucramiento que generen relaciones mas horizontales y democráticas al interior de la escuela (TOMÁs 2011, LÓPEZ 2012).

\section{RESUMEN Y COCLUSIONES}

Como contrapartida a la escuela bancaria tradicional, caracterizada por el autoritarismo y la fragmentación de la experiencia de aprendizaje, la escuela democrática propuesta por Freire propone una práctica de trabajo colectivo y solidario, la descentralización del poder, y un enfoque transdisciplinar de expresiones activas, participativas e incluyentes que parten del conocimiento del mundo que tienen los estudiantes en sus propias situaciones locales. En la propuesta freireana, los estudiantes amplían y profundizan su participación, y a través de esa participación aprenden por sí mismos a comprometerse como ciudadanos, y exploran las distintas maneras de poner en práctica los principios de la democracia y la justicia (SERNA 2016).

En sentido amplio, existen dos grandes vías para promover la participación de los estudiantes en las escuelas: la curricular y la organizativa. La primera tiene que ver con metodologías y contenidos que implican la participación del alumnado, e incluyen procesos deliberativos en el aula en los cuales se enfatiza la reflexión, el pensamiento crítico, la argumentación, el debate público y la escucha. Esta vía también puede incluir eventualmente una estructura curricular que les permita a los alumnos tomar algunas decisiones sobre su propio aprendizaje. La segunda vía se refiere a la democratización de la organización y gestión escolar a través de estructuras, espacios y procesos que le permitan al alumnado participar en la toma de decisiones de la institución en la medida de sus capacidades. La primera vía es la más común. Las experiencias desarrolladas en el aula (por ejemplo, las normas internas de funcionamiento del grupo) son las más frecuentes, lo cual se explica porque necesitan menos injerencia de otros actores más allá del docente de esa aula.

Para que la segunda vía se materialice y prospere se requiere de tiempo, paciencia y voluntad política. El sistema escolar no necesariamente rechaza los proyectos de educación para la participación, pero tiende a limitar su potencialidad educativa por tres razones. La primera, ya señalada, es la desconfianza sobre las capacidades de niños y jóvenes para tomar ciertas decisiones que deberían ser competencia de los adultos. La segunda es que estos programas no encajan bien en un sistema escolar basado en la lógica de las asignaturas, y la tercera es que no 
pueden ser fácilmente evaluados (MERCHÁN, 2005; GARCIA; PEREZ; DE ALBA, 2012). En este contexto, es preciso recordar que las escuelas democráticas, como la democracia misma, no se producen por casualidad. Se derivan de intentos explícitos de los educadores de generar oportunidades que darán vida a la democracia. Se trata de un proceso lento que se va dando progresivamente, y que consiste en ampliar y profundizar paulatinamente los espacios de participación de los estudiantes (APPLE; BEANE, 1999; SUSINOS RADA; CEBALLOS LÓPEZ, 2012). Uno de esos espacios es el presupuesto participativo escolar: si uno de los objetivos de la educación ciudadana es potenciar la cultura democrática, y si ello requiere reforzar algunos aspectos como la participación en procesos de deliberación y toma de decisiones (TIANA, 2008), el presupuesto participativo escolar puede hacer una modesta contribución a dicho objetivo.

Los presupuestos participativos se inscriben dentro del movimiento de las llamadas “escuelas ciudadanas", un movimiento del cual Freire ha sido una de las figuras centrales.

Las ecuelas ciudadanas asumen un compromiso social buscando mejorar la calidad de la enseñanza con el incremento de amplios procesos participativos y la construcción de la ciudadanía orientada hacia una perspectiva emancipadora (LOREA LEITE et al., 2012; FREIRE, 2001; GADOTTI, 2002). Así, la escuela ciudadana supone una práctica de democracia debido a su propia estructura y funcionamiento ya que el currículum que promueve genera oportunidades continuas para indagar en las cuestiones que afectan a sus participantes para crear respuestas a las problemáticas que van apareciendo. Estas escuelas, por una parte, deberían educar para la democracia y por otra, promover el ejercicio activo de la misma favoreciendo el paso de una cultura individualista a una colaborativa, generando una participación auténtica (APPLE; BEANE, 1999; CORNEJO; GONZÁLEZ; CALDICHOURY, 2007).

Los procesos participativos que permiten la construcción de espacios educativos y de empoderamiento colectivo están basados en un aprendizaje situado y activo que se conforma a partir de experiencias significativas para las participantes, fomentando el pensamiento crítico y la concientización, entre otros aprendizajes. Además se centran en experiencias que se llevan a cabo a través del diálogo, la discusión grupal, el liderazgo compartido y la cooperación manteniendo un papel problematizador de la realidad, con la finalidad de posibilitar su propio cuestionamiento. De este modo, la escuela ciudadana se sitúa como un espacio de aprendizaje dentro de una pedagogía democrática que promueve la participación comunitaria, la inclusión, la cooperación y 
la búsqueda del bien común (APPLE; BEANE, 1999, DIAZ-BARRIGA, 2003; CLAUS; OGDEN, 1999). Para que la participación sea auténtica es preciso garantizar que los protagonistas encuentren aquellos modos de organización y funcionamiento que sean más acordes con su contexto y sus necesidades (CORNEJO; GONZÁLEZ; CALDICHOURY, 2007). Así, herramientas como los presupuestos participativos escolares pueden favorecer el empoderamiento individual y la construcción colectiva a través de actitudes y capacidades como la confianza, la ayuda mutua, la conciencia ambiental, la curiosidad, la creatividad y la búsqueda del bien común por sobre los intereses particulares. Al expandir este tipo de procesos y prácticas de participación social, tanto en la escuela como en otros espacios, se aprende a afrontar y transformar la realidad social desde el espacio público, favoreciendo la construcción colectiva de una ciudadanía más activa, democrática y orientada a la justicia social.

\section{REFERENCIAS}

AGUIRRE, Arecia. Ciudades de papel: Etnografía Militante sobre la cultura de participación juvenil en la Casa de Joventut La Maranya. 2017. Tesis doctoral - Universitat Jaume I, Castellón , España.

ALBERICH, Tomás. Guía fácil de la participación ciudadana: Manual de gestión. Para el fomento de la participación ciudadana en ayuntamientos y asociaciones. Madrid, España: Dykinson, 2004.

ALBERICH, T.; ESPADAS, M. Asociacionismo, participación ciudadana, y políticas locales: planteamiento teórico y una experiencia práctica en Jaén. Revista Alternativas, 18, p.119-146, 2011.

ARANGUREN, Luis. La nueva órbita de la participación social. Madrid, España: Plataforma 2015, 2010..

APPLE, M. W.; BEANE, J. A. Escuelas democráticas. Madrid, España: Morata, 1999. ARMAS, J.; LOPEZ FACAL, R. Ciencias sociales y educación para la ciudadanía. Un diálogo necesario. Iber: Didáctica de las ciencias sociales, geografía e historia, n. 71, p. 84-92, 2012.

BAQUERO, Ricardo. Del experimento escolar a la experiencia educativa. La transmisión educativa desde una perspectiva psicológica situacional. Perfiles Educativos, n. 24(97-98), p. 57$75,2002$.

BENJAMIN, Shereen. The micropolitics of inclusive education: an ethnography. Estados Unidos: Open University Press, 2002. 
CALLE, Ángel. Democracia Radical. La construcción de un ciclo de movilización global. Jóvenes, globalización y movimientos altermundistas. Revista de Estudios de Juventud, (76), 2007.

CASSELS, A.; POST, L.; NESTOR, P. I. The 4-H club meeting: an essential youth development strategy. Journal of Extension, 53(1), p. 1-7, 2015.

COHEN, M.;SCHUGURENSKY, D.; WIEK. A. Citizenship education through participatory budgeting: the case of bioscience High School in Phoenix, Arizona. Curriculum and Teaching, 30:2, p. 5-26, 2015.

CLAUS, J.; OGDEN, C. An empowering, transformative approach to service. In: Claus J.; Ogden C. (Eds.). Service learning for youth empowerment and social change. Nueva York: Peter Lang, 1999. p. 69-94

CORNEJO, R.; GONZÁLEZ, J.; CALDICHOURY, J. Participación e incidencia de la sociedad civil en las políticas educativas: el caso chileno. Buenos Aires, Argentina: Fundación Laboratorio de Políticas Públicas, 2007.

COZZA, E.; SANTACHITA, S. La nueva secundaria y sus protagonistas: relevamiento de opiniones. In: SEIBOLDeibold, Jorge. (compilador). Escuela ciudadana y ciudad educadora en el marco del bicentenario. Buenos Aires: Crujía, 2011. p. 287-298.

DEWEY, John. Democracia y educación. Madrid, España: Morata, 1995.

DÍAZ-BARRIGA, Frida. Cognición situada y estrategias para el aprendizaje significativo. Revista electrónica de investigación educativa, n. 5(2), 2003.

FEITO, R.; LÓPEZ, J. I. Construyendo escuelas democráticas. Barcelona: Hipatia, 2008.

FISCHMAN, G.; GANDIN, L.. The pedagogical and ethical legacy of a successful educational reform: the citizen school project. International Review of Education, 62(1), p. 63-89, 2016.

FREIRE, Paulo. Concientización: teoría y práctica de la liberación. 3. ed. Bogotá, Colombia: Asociación de Publicaciones Educativas, 1997.

. Professora sim, tia não. Cartas a quem ousa ensinar. Sao Paulo: Olho dágua, 1997. . Pedagogía del oprimido. Buenos Aires: Siglo XXI, 1970.

. Educação e atualidade brasileira. Recife (tesis no publicada), 1959.

GALE, T.; DENSMORE, K. La implicación del profesorado. Una agenda de democracia radical para la escuela. Barcelona: Octaedro, 2007.

GADOTTI, Moacir. Escuela Ciudadana, Ciudad Educadora. Proyectos y prácticas en proceso, Revista CIAS, v. 51, n. 517, p. 504, 2002. 
GARCÍA PÉREZ, F.; ALBA FERNÁNDEZ, N. de. La educación para la participación ciudadana entre dos polos: el simulacro escolar y el compromiso social. In: ALBA FERNÁNDEZ, N. de; GARCÍA PÉREZ, F.; FERNANDÉZ A. S. (coord.). Educar para la participación ciudadana en la enseñanza de las Ciencias Sociales. Sevilla: Díada Editora, 2012. p. 297-306.

GERHARDT, Heinz. Paulo Freire. Perspectivas: revista trimestral de educación comparada. París, UNESCO, v. XXIII, n. 3-4, p. 463-484, 1993.

GUARRO, Amador. La transformación democrática de la cultura escolar: una respuesta justa a las necesidades del alumnado de zonas desfavorecidas. Revista de Currículum y Formación del Profesorado, n. 9(1), p. 1-48, 2005.

HERSEY, P.; BLANCHARD, K. H. Management of organizational behavior. Englewood: Prentice Hall, 1988.

INNERARITY, Daniel. Las ciudades en un mundo globalizado: hacia una nueva forma de ciudadanía. In: CONFERENCIA INAUGURAL XII - ENCUENTRO IBÉRICO DE DIRECTORES DE PLANES ESTRATÉGICOS URBANOS Y TERRITORIALES, 2016.

JAIMOVICH, Analía. Descentralización de la gestión escolar. Un estudio sobre el proyecto Escuela Ciudadana. In: Porto Alegre (Brasil) y el proyecto de escuelas autogestionadas de San Luis (Argentina). Informe final del concurso: Poder y nuevas experiencias democráticas en América Latina y el Caribe. Programa Regional de Becas, CLACSO, 2005.

KINCHELOE, J. L.; STEINBERG, S. R. Repensar el multiculturalismo. Barcelona: Octaedro. 1999.

LARRAURI, Maite. La educación según John Dewey. Valencia: Tàndem, 2012.

LAVE, J.; WENGER, É. Situated learning. Legitimate peripheral participation. New York: Cambridge University Press, 1991.

LEDERACH, John P. Preparing for Peace. Conflict transformation across cultures. Nueva York: Syracuse University Press, 1995.

LLENA, A., PARCERISA, A.; ÚCAR, X. 10 ideas clave: la acción comunitaria. Barcelona, España: GRAÓ, 2009.

LERNER, J.; SCHUGURENSKY, D. La dimensión educativa de la democracia local: el caso del presupuesto participativo. Revista Temas y Debates, 2007.

LÓPEZ, F.; LEÓN, L. La animación sociocultural como contribución a la construcción de la identidad comunitaria. Cuestiones pedagógicas. Revista de ciencias de la educación, n. 16, p. 139-150, 2009. 
LÓPEZ, Sergio. Los presupuestos participativos infantiles: implantación y alcance en España. In: V CONGRESSO MUNDIAL POR LOS DERECHOS DE LA INFANCIA Y ADOLESCENCIA. San Juan, Argentina, p. 15-19, oct. 2012.

LOREA LEITE, M. C. et al. Gestión escolar democrática. Una construcción contextualizada en escuelas municipales de la ciudad de Pelotas, RS, Brasil, 2012.

MERCHÁN, F.J. Enseñanza, examen y control. Profesores y alumnos en la clase de historia. Barcelona: Octaedro, 2005.

MOLINER, O. et al. Etrategias que inciden en los procesos de democratización de la escuela. Una aproximación teórica. Revista Electrónica de Investigación Educativa, n. 18(2), p. 116-129, 2016.

MUÑOZ, J. Manuel. (Ed.). Adolescencia y tiempo libre. Análisis y propuestas educativas en Salamanca. Salamanca, España: Universidad de Salamanca. 2011.

O'CADIZ, P.; WONG, P. L.; TORRES, C. A. Democracy and education. Paulo Freire, Social Movements, and Educational Reform in São Paulo. Westview Press, 1998.

OLIVER, Mike. Una sociología de la discapacidad o una sociología discapacitada. In: Barton, L. Discapacidad y sociedad. Madrid: Morata, 1998. p. 34-58.

PAÑO YÁÑEZ, Pablo. Analysis of participatory budgeting in Chile: a reflection of the national public policy evolution, 2014.

PATEMAN, Carole. Participation and democratic theory. Cambridge: Cambridge University Press, 1970.

PINEDA, C. Los presupuestos participativos en España: un nuevo balance. REALA: Revista de Estudios de la Administración Local y Autonómica. Madrid, 2009.

SAGÁSTEGUI, Diana. Una apuesta por la cultura: el aprendizaje situado. Sintética, 24, p. 30-40, 2004.

SCHUGURENSKY, Daniel. Paulo Freire. NY: Continuum, 2015.

SERNA, E. La transdisciplinariedad en el pensamiento de Paulo Freire. Revista de Humanidades n. 33, p. 213-243, 2016.

SERRANO, Jordi. Contra la democracia participativa. Los tramposos atajos hacia la participación democracia participativa. Barcelona, España: Fundació Ferrer i Guàrdia, 2008.

SUBIRATS, Joan. Democracia, participación y transformación social. Polis, 12. 2, 2005. 
SUSINOS RADA, T.; LÓPEZ, N. C. Voz del alumnado y presencia participativa en la vida escolar. Apuntes para una cartografía de la voz del alumnado en la mejora educativa. Revista de Educación, 359, p. 24-44, 2012.

TIANA, A. Deshaciendo equívocos: la Educación para la Ciudadanía en el contexto europeo. Idea La Mancha. Revista de Educación de Castilla-La Mancha, n. 6, p. 79-84, 2008.

TOMÁS, Catarina. A escola como um espaço de participação cidadã: orçamento participativo com crianças e jovens de Sevilha. In: COSTA E SOUZA, O.; CARDOSO, C.; DIA, M. (coord.), Formar professores, investigar práticas. Actas do IV Encontro do CIED, Lisboa, 2011.

TRAVER, J. A., SALES, A.; MOLINER, O. Ampliando el territorio: algunas claves sobre la participación de la comunidad educativa. Revista iberoamericana sobre Calidad, Eficacia y Cambio en Educación, n. 8 (3), p. 97-119, 2010.

VIEJO, R. et al. La participación ciudadana en la esfera pública: enfoques teórico-normativos y modelos de democracia. In: Parés (Eds.). Participación y calidad democrática: evaluando las nuevas formas de democracia participativa. Barcelona, España: Ariel, 2009. p. 29-54.

WACQUANT, Loic. (Ed.). Pierre Bourdieu and democratic politics. Polity Press, 2005.

WALKER, K.; SAITO, R. Youth are here: promoting Youth Spaces through Community mapping. Afterschool Matters, n. 14, p. 30-39, 2011.

WENGER, Éttiene. Comunidades de práctica: aprendizaje, significado e identidad. Madrid, España: Paidós, 2001.

ZAMORA, G. M. La democracia y la participación en la escuela:¿ cuánto se ha avanzado desde las normativas para promover la participación escolar? Revista de Estudios y Experiencias en Educación 10, n. 19, p. 107-129, 2016. 